dr hab. inz. Marian Medwid prof. nadzw.

mgr inz. Krzysztof Lukaszewski

mgr inz. Karol Bryk

Instytut Pojazdów Szynowych „,TABOR”

\title{
Symulacyjne komputerowe badania dynamiczne modułowego pojazdu do transportu kombinowanego, kolejowo-drogowego
}

\begin{abstract}
W artykule przedstawiono wyniki symulacyjnych badań dynamicznych „Modułowego sytemu transportu kombinowanego", stużacego do przewozu naczep siodtowych. Z racji specyficznej konstrukcji platform do transportu kombinowanego konieczne jest sprzęnięcie dwóch takich pojazdów. W innym przypadku nie byto by możliwe skonfigurowanie pociagu w skład którego wchodzq inne wagony, dlatego omawiane badania zostały przeprowadzone właśnie dla takiego składu.

Zaprezentowano sposób przeprowadzenia oraz wyniki badań odnoszacych się do stabilności ruchu pojazdu, badań liniowych (eksploatacyjnych) obejmujacych bezpieczeństwo jazdy, obciqżenie toru i spokojność biegu. Podczas badań liniowych wykonano serię przejazdów po prostej jak $i$ w tuku przy uwzględnieniu rzeczywistych, zmierzonych nierówności toru. Badania zostaty przeprowadzone $w$ oparciu o wymagania zawarte w normie PN-EN-14363.

Scenariusze badań oraz wyniki odnoszqce się do pojazdu modułowego do transportu kolejowo-drogowego, prezentowane $w$ referacie, sa wynikiem prac badawczych przeprowadzonych $w$ ramach realizacji projektu rozwojowego $\mathrm{nr}$ R10-0065-10 „System transportu naczep drogowych na wózkach kolejowych $w$ kombinowanym ruchu kolejowo-drogowym".
\end{abstract}

\section{OBIEKT BADAŃ}

Obiektem badań jest platforma do transportu kombinowanego (dalej zwana bimodalna) (rys.1) przeznaczona do przewozu naczepy ciagnika siodłowego. Konstrukcja analizowanej platformy składa się z sześciu podstawowych elementów, które przedstawiono na rysunku 2: trzech wózków jezdnych 1, platformy pod koła naczepy 2 , ramy pod gniazdo naczepy 3 , elementu łącznikowego pomiędzy platformą a ramą pod gniazdo 4 . Element łącznikowy 4 połączony jest $\mathrm{z}$ platformą pod koła naczepy 2 za pomoca przegubu kulistego $4 \mathrm{a}$, a $\mathrm{z}$ ramą naczepy 3 za pomocą dwóch sworzni $4 \mathrm{~b}$.

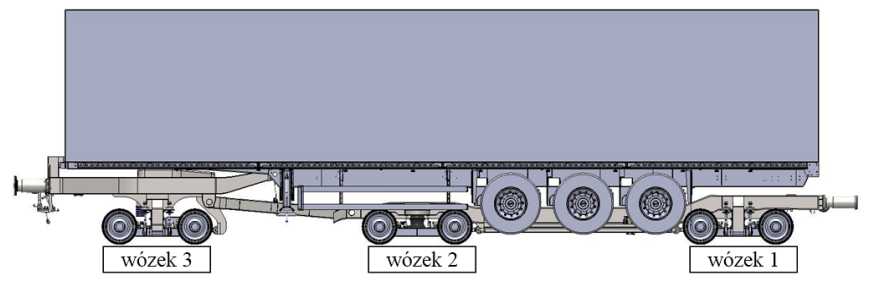

Rys. 1 - Platforma bimodalna wraz z naczepą ciągnika siodłowego

Naczepa jest połączona $\mathrm{z}$ ramą pod gniazdo naczepy w pięciu punktach (rys. 3) które razem tworzą sztywne połączenie pomiędzy tymi elementami.

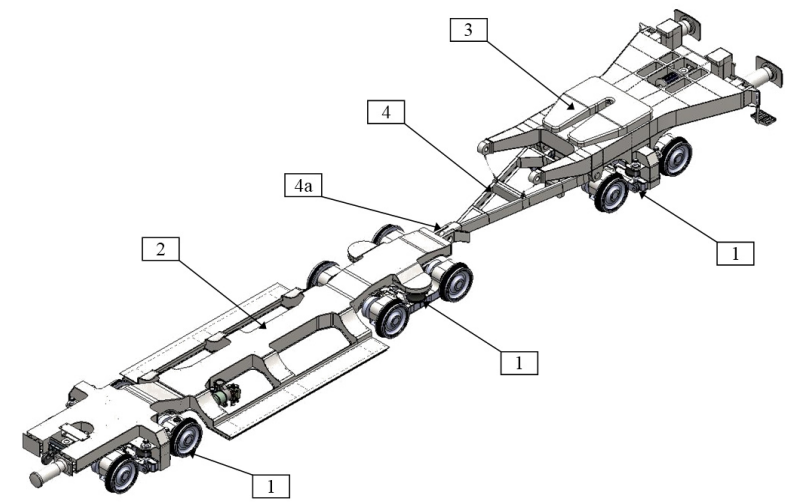

Rys. 2 - Widok platformy bimodalnej bez naczepy

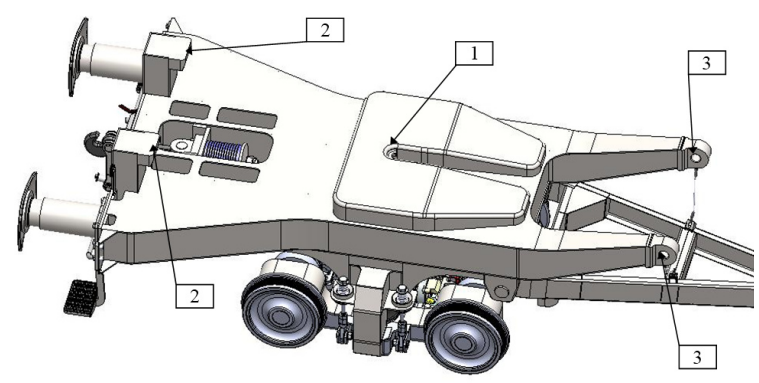

Rys. 3 - Miejsca połączenia naczepy z ramą: 1 - mocowania czopu naczepy, 2 - ograniczniki pionowe, 3 - otwory pod sworznie łączące 
Analizowany pojazd wyposażony jest w trzy wózki (rys. 4) o bazie 1,36 m zaopatrzone w zestawy kołowe z kołami o średnicy $580 \mathrm{~mm}$. Pierwszy stopień usprężynowania stanowią przekładki gumowe 1 znajdujące się pomiędzy maźnicami zestawów kołowych a ramą wózka. Omawiane przekładki gumowe zastosowano w celu uzyskania pożądanych wartości sztywności prowadzenia zestawów kołowych w kierunku wzdłużnym i poprzecznym. Ze względu na dużą wartość sztywność pionowej, elementy te nie mają wpływu na dynamikę pionową pojazdu. Drugi stopień usprężynowania stanowią sprężyny gumowo metalowe 2, elementy te umożliwiaja dodatkowo obrót wózka względem nadwozia pojazdu. W drugim stopniu występuje również thumik drgań poprzecznych 3. Siła trakcyjna i hamująca pomiędzy wózkiem a nadwoziem pojazdu przekazywana jest przez cięgło 4 (rys. 5). W pojeździe przewidziano również zastosowanie thumików wężykowania zainstalowanych pomiędzy ramami wózków a nadwoziem platformy.

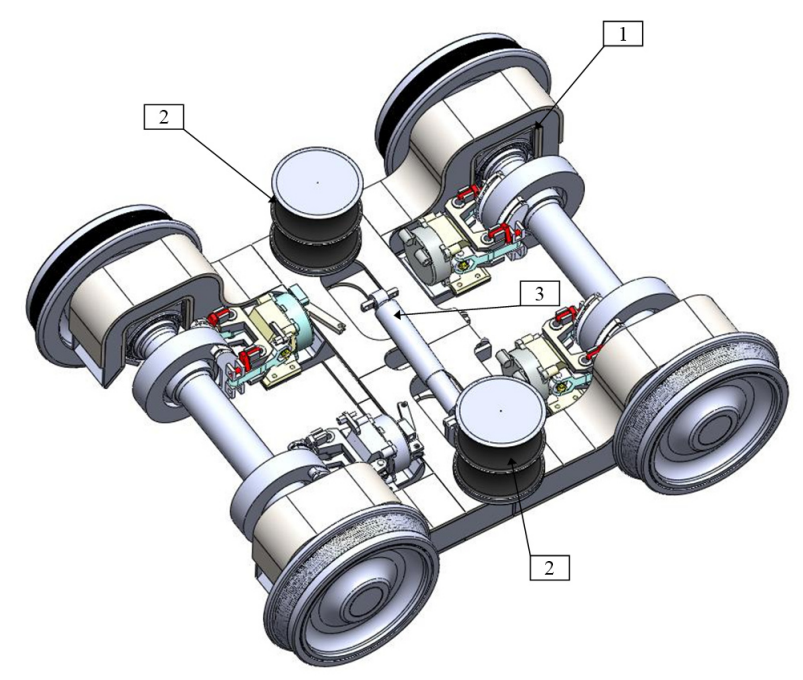

Rys. 4 - Widok wózka platformy bimodalnej (bez thumików wężykowania)

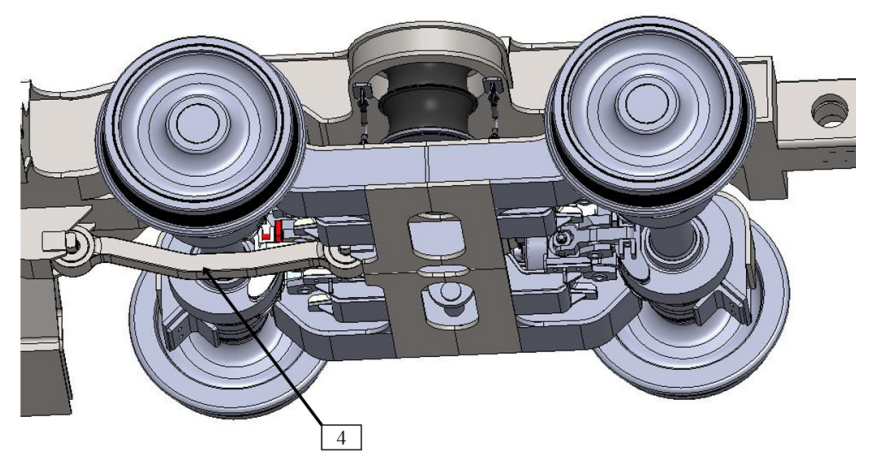

Rys. 5 - Widok wózka platformy bimodalnej (bez tłumików wężykowania)

\section{MODEL MECHANICZNY}

Model mechaniczny analizowanego pojazdu składa się z brył sztywnych połączonych elementami podatnymi oraz elementami łączącymi umożliwiającymi wprowadzenie więzów pomiędzy bryłami. W celu zapewnienia odpowiednich dokładności modelu nadwozie naczepy, platforma pod koła na-czepy oraz ramy wózków zostały podzielone na odpowiednią ilość brył sztywnych tak aby było możliwe wprowadzenie pomiędzy analizowanymi bryłami sztywności odzwierciedlających realne wartości podatności tych elementów.

Na rysunku 6 pokazano schemat wzajemnych powiązań kinematycznych brył sztywnych pojazdu.

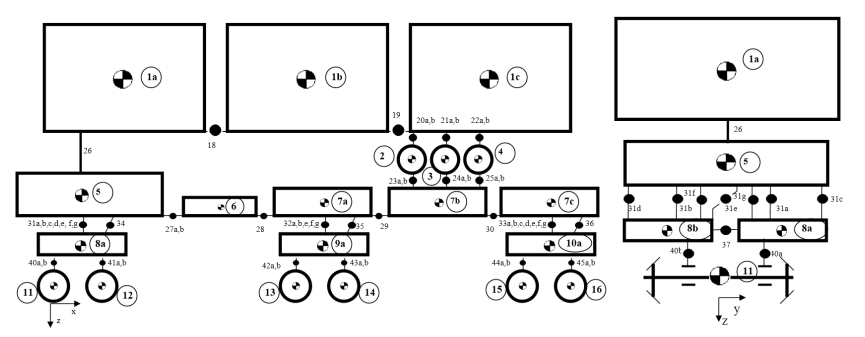

Rys. 6 - Schemat mechaniczny pojazdu bimodalnego

Na podstawie opracowanego modelu mechanicznego zbudowano w programie SIMPACK model analizowanego pojazdu bimodalnego tak jak pokazano na rysunku 7.

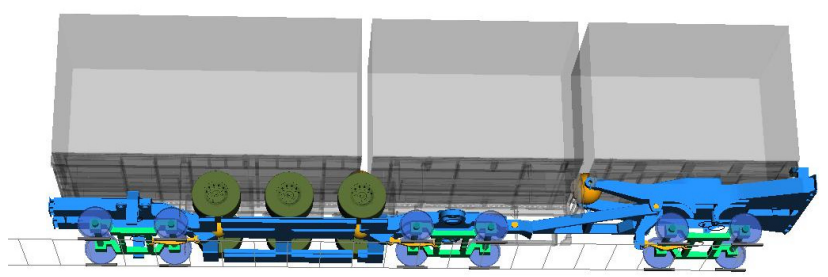

Rys. 7 - Widok modelu platformy bimodalnej wraz z naczepą w programie SIMPACK

\section{ANALIZA UZYSKANYCH PRZEBIEGÓW}

Badanie stabilności ruchu pojazdu zostało wykonane na podstawie obserwacji odpowiedzi pojazdu na zadane wstępnie wychylenie od osi toru. Uzyskane wyniki zamieszczono w tabeli 1 . W pierwszej fazie badań poddano analizie skład załadowany pustymi naczepami. Przy prędkości $138 \mathrm{~km} / \mathrm{h}$, ruch pojazdu z pustymi naczepami jest stabilny. Ponieważ po wychyleniu zestawów kołowych z osi toru (przejazd przez odpowiednio przygotowany krótki odcinek toru) występują zanikające drgania, w efekcie pojazd wraca do osi toru. Wyniki uzyskane dla przejazdu z prędkością $145 \mathrm{~km} / \mathrm{h}$, w tej sytuacji ruch pojazdu jest już nie stabilny. Analogicznie w tej samej tabeli (tab. 1) pokazano otrzymane przebiegi wychylenia poprzecznego zestawów kołowych dla składu z naczepami załadowanymi przy prędkości odpowiednio 160 $\mathrm{km} / \mathrm{h}$ oraz $165 \mathrm{~km} / \mathrm{h}$, przy pierwszej $\mathrm{z}$ podanych prędkości ruch pojazdu jest nadal stabilny. $Z$ przedstawionych przebiegów można wnioskować ze prędkość krytyczna pojazdu wynosi $138 \mathrm{~km} / \mathrm{h}$. 
W celu sprawdzenia celowości zastosowania thumików wężykowania przeprowadzono dodatkowy analizę stabilności ruchu modelu pojazdu z wyłączonymi tłumikami wężykowania. Prędkość krytyczna składu pustych pojazdu bez tłumików wężykowania wynosi $100 \mathrm{~km} / \mathrm{h}$.

\begin{tabular}{|c|c|c|c|}
\hline Lp & Stan & $\begin{array}{c}\text { Prędko } \\
\text { ść } \\
{[\mathbf{k m} / \mathbf{h}]}\end{array}$ & $\begin{array}{l}\text { Przemieszczenie poprzeczne trzeciego zestawu } \\
\text { kolowego pierwszego wagonu }\end{array}$ \\
\hline 1. & $\begin{array}{l}\text { Naczepy } \\
\text { puste z } \\
\text { thumikami }\end{array}$ & 138 & ヘヘmルaman \\
\hline 2. & $\begin{array}{l}\text { Naczepy } \\
\text { puste z } \\
\text { thumikami }\end{array}$ & 145 & 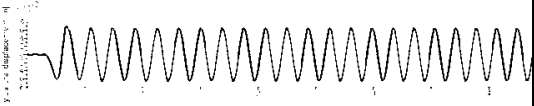 \\
\hline 3. & $\begin{array}{l}\text { Naczepy } \\
\text { załadowa } \\
\text { ne z } \\
\text { thumikami }\end{array}$ & 160 & ๓๐: : : \\
\hline 4. & $\begin{array}{l}\text { Naczepy } \\
\text { załadowa } \\
\text { ne z } \\
\text { tłumikami }\end{array}$ & 165 & NMmmmmmmmanmm \\
\hline 5. & $\begin{array}{l}\text { Naczepy } \\
\text { puste bez } \\
\text { tłumików }\end{array}$ & 100 & $=\quad: \quad: \quad<\quad:$ \\
\hline 6. & $\begin{array}{l}\text { Naczepy } \\
\text { puste bez } \\
\text { thumików }\end{array}$ & 105 & 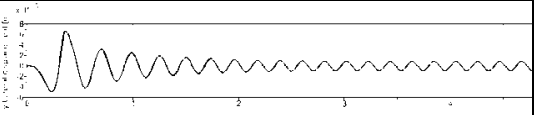 \\
\hline
\end{tabular}

Badania linowe zostały przeprowadzone na podstawie wytycznych zawartych w normie PN-EN 14363, zrealizowano scenariusz normalnej metody pomiarowej. Omawiane badania składają się z trzech części:

- bezpieczeństwo jazdy;

- obciążenie toru;

- własności dynamiczne (spokojność biegu).

Podczas badań wykonano serię symulacji przejazdu składu z pełnymi i pustymi naczepami po czterech odcinakach toru, realizujących charakterystykę zmierzoną na torze rzeczywistym.

Tory badawcze:

- tor 1, prosty odcinek toru;

- tor 2 , łuk o dużym promieniu $(\mathrm{R}=$ $800 \mathrm{~m}$, przechyłka $120 \mathrm{~mm}$ );

- tor 3, łuk o małym promieniu ( $\mathrm{R}=$ $500 \mathrm{~m}$, przechyłka $150 \mathrm{~mm}$ );

- tor 4, łuk o bardzo małym promieniu $(\mathrm{R}=250 \mathrm{~m}$, przechyłka $150 \mathrm{~mm})$.

$\mathrm{Na}$ poszczególnych torach badawczych wykonano przejazdy z następującymi prędkościami:

- tor $1,110 \% \mathrm{~V}_{\max }=132 \mathrm{~km} / \mathrm{h}$;

- tor $2,122 \mathrm{~km} / \mathrm{h}$;

- tor $3,105 \mathrm{~km} / \mathrm{h}$;

- tor $4,72 \mathrm{~km} / \mathrm{h}$.

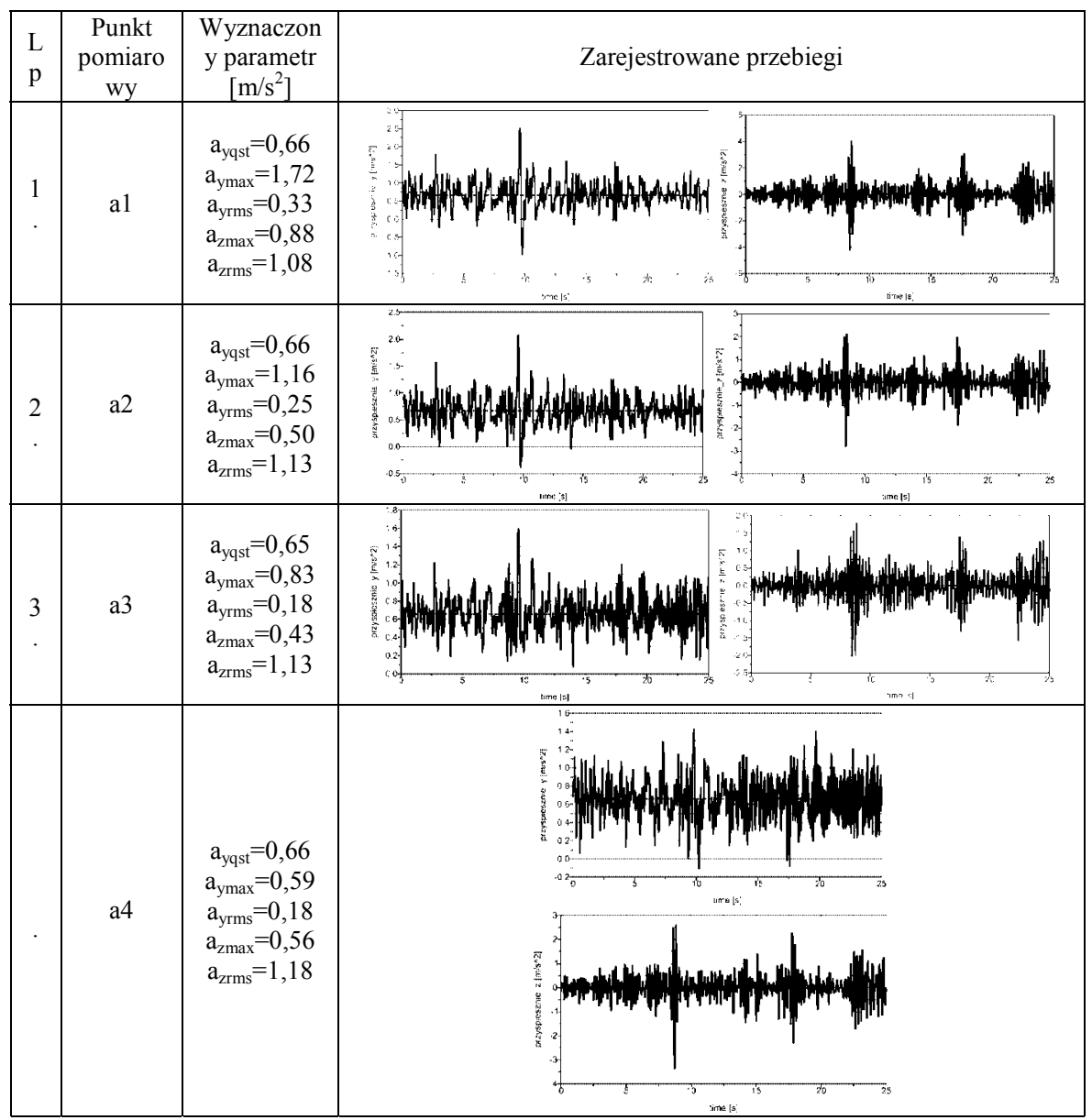


Dla przejazdów realizowanych na torze $2,3 \mathrm{i}$ 4 niezrównoważone przyspieszenie boczne wynosi $0,66 \mathrm{~m} / \mathrm{s}^{2}\left(0,6 \mathrm{~m} / \mathrm{s}^{2}+10 \%\right.$, odpowiada to niedoborowi przechyłki na poziomie $99.6 \mathrm{~mm})$.

Przykładowe wyniki przedstawione w tabeli 2 otrzymano w punktach pomiarowych z rysunku 8 .

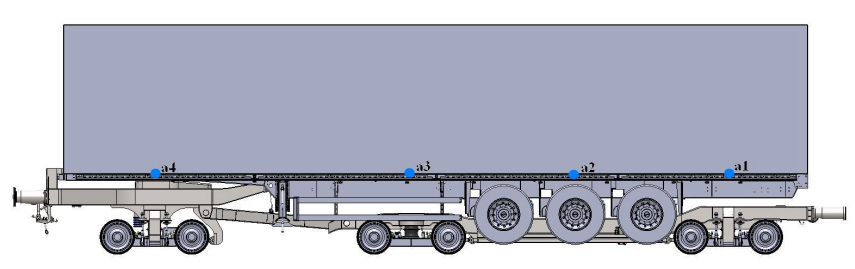

Rys. 8 - Rozmieszczenie punktów pomiarowych dla wagonu pierwszego (a), dla pozostałych wagonów punkty pomiarowe rozmieszczono analogicznie

\section{PODSUMOWANIE I WNIOSKI}

Przedstawione badania symulacyjne zostały wykonane w oparciu o wymagania zawarte w normie PN-EN-14363.

W części dotyczącej badań liniowych wykonano serię przejazdów po rzeczywistym torze, zarówno prostym jak i w łuku. Wyniki uzyskane dla bezpieczeństwa jazdy spełniają wymagania zawarte $\mathrm{w}$ normie [1], gorsze parametry otrzymane podczas przejazdu po łuku, częściowo wynikają z wyczerpania luzu pomiędzy ramą wózka a odbijakami ograniczającymi przesuw poprzeczny wózka, co powoduje duży wzrost sztywności poprzecznej. Analiza stabilności ruchu pojazdu przeprowadzona metodą obserwacji odpowiedzi układu na wymuszenia impulsowe jak i poprzez analizę siły prowadzącej na zestawach kołowych podczas przejazdu przez tor rzeczywisty wykazała, że pojazd do prędkości maksymalnej 120 $\mathrm{km} / \mathrm{h}$ (plus $10 \%$ wymagane przez normę) nie wykazuje tendencji do niestabilności ruchu, wyznaczona prędkość krytyczna pojazdu wynosi $138 \mathrm{~km} / \mathrm{h}$. W przypadku pojazdu niewyposażonego w thumiki wężykowania maksymalna prędkość eksploatacyjna może wynosić tylko $90 \mathrm{~km} / \mathrm{h}$ i wynika z pojawiania się niestabilności ruchu przy prędkości około 100 $\mathrm{km} / \mathrm{h}$ dla platformy bimodalnej z pustymi naczepami.
Wyniki obliczeń symulacyjnych pojazdu bimodalnego przedstawione $\mathrm{w}$ niniejszym opracowaniu pozwalają pozytywnie ocenić obciążenie toru spowodowane przejazdem analizowanego pojazdu. Wszystkie wymagane wielkości odnoszące się do obciążenia toru są spełnione $\mathrm{z}$ dużym zapasem bezpieczeństwa.

Przeprowadzone symulacje wykazały że analizowany pojazd wykazuje wystarczającą spokojność biegu do prędkości maksymalnej. Podobnie jak w przypadku bezpieczeństwa jazdy nieco gorsze parametry uzyskano podczas przejazdu w łuku, wynikają one $\mathrm{z}$ wyczerpania luzu poprzecznego $\mathrm{w}$ zawieszeniu drugiego stopnia.

Podsumowując można stwierdzić że analizowany model pojazdu bimodalnego do prędkości 120 $\mathrm{km} / \mathrm{h}(120 \mathrm{~km} / \mathrm{h}+10 \%)$ spełnia wymagania zawarte w normie PN-EN-14363.

\section{Bibliografia}

[1] PN-EN 14363: Kolejnictwo. Badania wtasności dynamicznych dla dopuszczenia (homologacji) pojazdów szynowych. Badania własności biegowych i próby stacjonarne. PKN, Warszawa 2007

[2] Kodeks UIC 530-2: Wagony towarowe Bezpieczeństwo jazdy, Międzynarodowy Zwiazek Kolei UIC, 2011

[3] Medwid M.: Polski system transportu kolejowodrogowego (bimodalnego) typu TABOR, Wydawnictwo IPS “TABOR”, Poznań 2006

[4] Madej J., Medwid M.: Modulowy system transportu naczep siodłowych na wózkach kolejowych w ruchu kombinowanym kolejowo-drogowym, Pojazdy Szynowe, IPS “TABOR”, Poznań 02/2013 